\title{
EL FENÓMENO DE LA TRATA DE MENORES DE EDAD EN LOS INSTRUMENTOS JURÍDICOS INTERNACIONALES: AVANCES Y RETOS PENDIENTES
}

\section{TRAFFICKING IN CHILDREN IN THE INTERNATIONAL LEGAL INSTRUMENTS: PROGRESSES AND PENDING CHALLENGES}

\author{
Josune López Rodríguez. Universidad de Deusto - España \\ josunelopezrodriguez@deusto.es \\ Demelsa Benito Sánchez. Universidad de Deusto - España \\ demelsa.benito@deusto.es
}

\begin{abstract}
Resumen La trata de menores es un fenómeno mundial que vulnera los derechos humanos de las víctimas. Para combatirlo, diversas organizaciones internacionales y regionales han adoptado instrumentos jurídicos vinculantes que imponen a los Estados determinadas obligaciones. Este trabajo analiza la forma en la que estos instrumentos han abordado el fenómeno, con la finalidad última de detectar los avances más significativos y los retos pendientes. A tal fin, se parte del estudio del concepto de trata de menores. A continuación, se estudian los instrumentos jurídicos internacionales y regionales que se han ido adoptando a lo largo de más de un siglo, prestando especial atención a los tres más relevantes: el Protocolo de Palermo, el Convenio de Varsovia y la Directiva 2011/36/UE. A partir de este estudio, se destacan los avances más importantes en la materia y se señalan los desafíos pendientes para una lucha más eficaz contra este fenómeno. Por último, se exponen las principales conclusiones del trabajo.
\end{abstract}

Palabras clave Menores, instrumentos jurídicos internacionales, derechos humanos, trata, explotación.

\begin{abstract}
Trafficking in children is a worldwide phenomenon that violates the human rights of the victims. In order to combat it, several international and regional organisations have adopted a number of binding legal instruments that impose States certain obligations. This paper analyses the way these instruments have addressed this phenomenon, in order to detect the most important progresses and pending challenges. To that end, this paper stems from the study of the concept of trafficking in children. Then, it analyses the international and regional legal instruments adopted during most than one century, paying special attention to the three most relevant: the Palermo Protocol, the Warsaw Convention, and the Directive 2011/36/EU. From this study, the paper underlines the most important progresses in this field and it also emphasizes the pending challenges regarding a more effective fight against this phenomenon. Finally, the paper offers the main conclusions of the study.
\end{abstract}

Key words Children; international legal instruments; human rights; trafficking; exploitation. 


\section{Introducción}

La trata de menores de edad no es un fenómeno nuevo; sin embargo, éste sigue constituyendo un problema de actualidad en pleno siglo XXI. Si bien existe un consenso internacional sobre la urgente necesidad de erradicar esta grave violación de derechos humanos, lo cierto es que las medidas adoptadas hasta el momento para combatir la trata de personas, en general, y la trata de menores, en particular, no han logrado este objetivo. A mayor abundamiento, la trata de personas, lejos de constituir un delito aislado, se presenta en el actual contexto mundial como una práctica frecuente y una de las actividades ilícitas más lucrativas.

Esta problemática ha sido puesta de manifiesto en la Agenda 2030 para el Desarrollo Sostenible, aprobada mediante la Resolución de la Asamblea General de las Naciones Unidas de 25 de septiembre de 2015, que comprende 17 objetivos a través de los cuales se persigue la consecución de un desarrollo sostenible basado en la armonización de la justicia social, la sostenibilidad ambiental y el progreso económico. En concreto, en el marco de esta Agenda internacional, se urge a los Estados a «adoptar medidas inmediatas y eficaces para erradicar el trabajo forzoso, poner fin a las formas contemporáneas de esclavitud y la trata de personas y asegurar la prohibición y eliminación de las peores formas de trabajo infantil, incluidos el reclutamiento y la utilización de niños soldados, y, de aquí a 2025, poner fin al trabajo infantil en todas sus formas» (cfr. objetivo 8.7) y a «poner fin al maltrato, la explotación, la trata y todas las formas de violencia y tortura contra los niños» (cfr. objetivo 16.2).

A grandes rasgos, la ORgANIZACIÓn INTERNACIONAL DEL TRABAJO estima que alrededor de 1,2 millones de menores son víctimas de trata en todo el mundo ${ }^{1}$. Por su parte, la ORGANIZACIÓN INTERNACIONAL PARA LAS MIGRACIONES advierte que este fenómeno se desarrolla en todas las regiones del mundo, si bien su dimensión varía considerablemente de una región a otra ${ }^{2}$. A este último respecto, la OFICINA DE LAS NACIONES UNIDAS CONTRA LA DROGA Y EL DELITO señala que, por lo general, el volumen de la trata de menores es especialmente llamativo en el África subsahariana y en la región de Centro América y el Caribe. Asimismo, el volumen de la trata de menores es alto en otras regiones como el Norte de África, Oriente Medio, América del Sur, el Sur Este Asiático y el Pacífico ${ }^{3}$. En lo que a la Unión Europea se refiere, el CENTRO DE INVESTIGACIONES INNOCENTI de UNICEF confirma que la trata de menores afecta a la práctica totalidad de los Estados Miembros ${ }^{4}$.

\footnotetext{
${ }^{1}$ ORGANIZACIÓN INTERNACIONAL DEL TRABAJO (2002, p. 25).

2 ORGANIZACIÓN INTERNACIONAL PARA LAS MIGRACIONES (2012, p. 22).

3 OFICINA DE LAS NACIONES UNIDAS CONTRA LA DROGA Y EL DELITO (2016, p. 11).

${ }^{4}$ UNICEF CENTRO DE INVESTIGACIONES INNOCENTI (2008, p. 8).
} 
En principio, estas cifras manifiestan la alarmante presencia de la trata de menores en todo el globo. No debe olvidarse, sin embargo, que estas referencias constituyen una mera aproximación a la realidad del fenómeno, ya que no existen a día de hoy estadísticas contundentes y fiables sobre su verdadera magnitud. Esta ausencia se fundamenta, principalmente, en las dificultades para cuantificar una práctica de naturaleza criminal como ésta, en las diferencias legislativas entre los ordenamientos internos en materia de trata y en la inexistencia de métodos uniformes para la recogida de información sobre los casos detectados ${ }^{5}$.

Partiendo de estos antecedentes, el presente artículo tiene por objeto analizar cómo se ha abordado el fenómeno de la trata de menores en los instrumentos jurídicos internacionales, con el fin último de destacar los avances más significativos logrados hasta el momento y de detectar, al mismo tiempo, los retos pendientes. A tal fin, primero, se concretará el concepto del fenómeno, distinguiéndose su significado y sus elementos principales. Una vez delimitado el marco conceptual, se hará un repaso por los instrumentos jurídicos internacionales más importantes que han abordado la trata de menores. Con base en este análisis, a continuación, se resaltarán los avances más significativos en la materia y se señalarán cuáles son los desafíos pendientes para avanzar hacia la erradicación de la trata de menores. Por último, se expondrán las conclusiones del análisis realizado.

\section{Concepto de la trata de menores de edad en el ordenamiento jurídico internacional}

El estudio del fenómeno de la trata de menores en los instrumentos jurídicos internacionales requiere prestar atención, antes de nada, a su significado y a sus elementos constitutivos.

\subsection{Significado}

En el actual marco jurídico internacional, el concepto predominante de la trata de personas es el dispuesto en el Protocolo para prevenir, reprimir y sancionar la trata de personas, especialmente mujeres y niños, que complementa la Convención de las Naciones Unidas contra la Delincuencia Organizada Transnacional, hecho en Nueva York el 15 de noviembre de 2000 (en adelante, Protocolo de Palermo) ${ }^{6}$. En el mismo, la trata de personas se define como «la captación, el transporte, el traslado, la acogida o la recepción de personas, recurriendo a la amenaza o al uso de la fuerza u otras formas de coacción, al rapto, al fraude, al engaño, al abuso de poder o de una situación de vulnerabilidad o a la concesión o recepción de pagos o beneficios para obtener el

\footnotetext{
${ }^{5}$ Véase Mier Hernández, A. y Rodríguez-Argüelles, S. (2011, p. 198). Para un análisis detallado de los problemas en relación con la recogida de datos fiables en materia de trata de seres humanos, veánse los resultados del proyecto FIDUCIA - "New European Crimes and Trust-based Policy", en particular, JokineN, A., VIUHKO, M., NIKKILÄ, M., JOUTSEN, M., CAMPANA, P. y BeNITO, D. (2014, pp. 24-37).

${ }^{6}$ Entró en vigor el 25 de diciembre de 2003.
} 
consentimiento de una persona que tenga autoridad sobre otra, con fines de explotación ${ }^{7}$, puntualizándose que «la captación, el transporte, el traslado, la acogida o la recepción de un niño con fines de explotación se considerará "trata de personas" incluso cuando no se recurra a ninguno de los medios enunciados»" ${ }^{8}$. En el contexto de este instrumento internacional, por «niño» ${ }^{9}$ debe entenderse toda persona menor de dieciocho años.

Al margen de las limitaciones y carencias del Protocolo de Palermo, instrumento que se enmarca exclusivamente en el ámbito de la delincuencia organizada transnacional, la definición adoptada constituye el punto de partida de la noción actual de la trata de personas. A partir de este momento, la trata empieza a concebirse como un fenómeno multifacético y se supera, finalmente, su exclusiva identificación con la trata de mujeres, niños y niñas con fines de explotación sexual ${ }^{10}$, aunque esta forma de trata siga representando un porcentaje muy importante ${ }^{11}, y$ dentro de ésta, la inmensa mayoría de víctimas son mujeres y niñas ${ }^{12}$.

En el contexto europeo, tanto en el seno del Consejo de Europa como en el ámbito de la Unión Europea, la normativa vigente sobre la trata de personas toma como referencia la definición del Protocolo de Palermo e introduce algunos matices importantes para complementarla ${ }^{13}$. Sin duda alguna, las aportaciones más significativas son la extensión del significado de la trata más allá de la delincuencia organizada transnacional y su consideración, ante todo, como grave vulneración de los derechos humanos.

Por un lado, en el marco del Consejo de Europa, el Convenio sobre la lucha contra la trata de seres humanos, hecho en Varsovia el 16 de mayo de 2005 (Convenio de

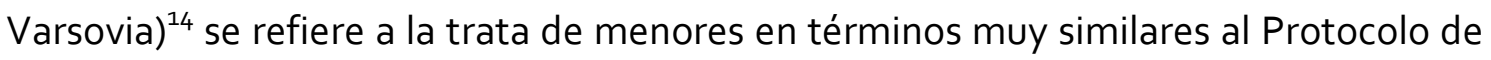
Palermo, como «la contratación, el transporte, el traslado, el alojamiento o la acogida de un niño con fines de explotación ${ }^{15}$, entendiéndose que «el término "niño" designa

\footnotetext{
${ }^{7}$ Artículo 3.a).

${ }^{8}$ Artículo 3.c).

${ }^{9}$ Artículo 3.d).

${ }^{10}$ VILLACAMPA ESTIARTE, C. (2011a, p. 34).

${ }^{11}$ En este sentido, y aunque las cifras en relación con el fenómeno de la trata no sean muy exactas por los motivos ya apuntados, el último informe sobre la trata de seres humanos elaborado por Eurostat señala que, en el ámbito de la Unión Europea, un 69\% de las víctimas de trata lo son con la finalidad de explotación sexual, un $19 \%$ con la finalidad de explotación laboral y un $12 \%$ con otras finalidades (extracción de órganos, actividades delictivas, venta de niños). EUROSTAT (2015, p. 11).

${ }^{12}$ En concreto, un 95\% según el informe de Eurostat. (Ibid.).

${ }^{13}$ Pérez Cepeda, A.I. y Benito SÁnChez, D. (2014, p. 17).

${ }^{14}$ Entró en vigor el 1 de febrero de 2008.

${ }^{15}$ Artí́culo 4.C).
} 
a toda persona de menos de dieciocho años de edad» ${ }^{16}$. En este texto también se señala que cuando la trata afecte a los menores de edad no es indispensable recurrir a los medios propios de la trata de personas.

Y, por otro lado, en el ámbito de la Unión Europea, la Directiva 2011/36/UE del Parlamento Europeo y del Consejo, de 5 de abril de 2011, relativa a la prevención y lucha contra la trata de seres humanos y a la protección de las víctimas y por la que sustituye la Decisión Marco 2002/629/JAI del Consejo ${ }^{17}$, determina que cuando se produzca la captación, el transporte, el traslado, la acogida o la recepción, incluido el intercambio o la transferencia de control sobre las personas, de un menor de edad con el fin de explotarlo, esta conducta «constituirá infracción punible de trata de seres humanos ${ }^{18}$. Al igual que el Protocolo de Palermo y el Convenio de Varsovia, la Directiva dispone que el delito de trata de menores no requiere la presencia de los medios típicos. La Directiva de la Unión Europea, por su parte, merece ser destacada en tanto que es el primer documento en la materia que reconoce la especificidad del fenómeno de la trata en función del sexo de la víctima, indicando que hombres y mujeres son objeto de trata con diferentes fines (cfr. considerando 3), e instando, por lo tanto, a los Estados Miembros a elaborar políticas de prevención con perspectiva de género (cfr. considerando 25).

En definitiva, la trata de personas, en general, y de menores, en particular, constituye una grave vulneración de los derechos humanos, vulneración que incide con más fuerza sobre las mujeres y niñas en tanto que es evidente el «sesgo de género del fenómeno ${ }^{19}$. Especialmente, este fenómeno atenta contra la dignidad, la vida y la integridad física, el bienestar y el desarrollo de los menores de edad, así como contra su derecho a ser protegidos de la explotación.

\subsection{Elementos principales}

A partir de las disposiciones de los tres instrumentos mencionados, puede deducirse que la trata de personas adultas comprende tres elementos principales (esto es, una acción determinada, el empleo de medios coercitivos, fraudulentos o abusivos para efectuar dicha acción, y la intención de explotar a la víctima), mientras que la trata de menores solamente integra dos de estos elementos (a saber, la acción y la finalidad $)^{20}$. En este último caso, no se requiere la presencia de medios que anulen la voluntad de la víctima por entender que los menores de edad son especialmente vulnerables ante la trata y que, además, no tienen la capacidad jurídica para otorgar

\footnotetext{
${ }^{16}$ Artículo 4.d).

${ }^{17}$ DOUE L 101 de 15 de abril de 2011.

${ }^{18}$ Artículo 2.5 .

${ }^{19}$ VelAsCo PorTERO, M.T. (2012, p. 7).

${ }^{20}$ Badia MARTí, A.M. (2010, pp. 124-125) y PéRez GonZÁlez, C. (2014, p. 71).
} 
un consentimiento válido ${ }^{21}$. De este modo, en el marco de la trata de menores de edad, la minoría de edad de la víctima presupone la concurrencia de medios que anulan su voluntad ${ }^{22}$.

Así, por un lado, la acción propia de la trata de menores consiste en captar, reclutar, transportar, trasladar, transferir, recibir, acoger o alojar a una persona menor de dieciocho años. En concreto, estas acciones describen la trata como un proceso que comienza con la captación o el reclutamiento del menor en un determinado lugar, continúa con su transporte, traslado o transferencia, hasta que se produce su recepción, acogida o alojamiento en el lugar de destino ${ }^{23}$. Mediante la realización de estas acciones, se produce una transferencia de control sobre la víctima ${ }^{24}$.

Con respecto al procedimiento de ejecución de la acción, es importante adelantar que no existe un modelo único de trata de menores de edad sino que su desarrollo depende de una multitud de factores ${ }^{25}$.

En primer lugar, este fenómeno comienza con la captación o reclutamiento de una persona menor de edad. Por lo general, la captación puede llevarla a cabo cualquier persona, es decir, un miembro de la familia, una persona conocida o una persona desconocida, que puede actuar tanto de manera individual como en coordinación con terceras personas. Es más, a veces, la acción es efectuada por alguien que pertenece a un grupo criminal organizado. Si bien la captación y el reclutamiento de menores puede producirse en cualquier contexto y en cualquier lugar del mundo, existen determinadas circunstancias que favorecen la consecución de este fenómeno como, por ejemplo, los contextos de extrema pobreza, los conflictos armados, algunas prácticas tradicionales como los matrimonios concertados, la falta de educación, la desestructuración familiar, la delincuencia organizada, o las catástrofes naturales ${ }^{26}$. A mayor abundamiento, esta acción puede llevarse a cabo de muy diversos modos, dependiendo de la edad de la víctima, de su sexo, de su entorno, de sus necesidades, etc. A veces, los tratantes se aprovechan de la precaria situación económica en la que se encuentran algunas familias ofreciéndoles una salida laboral para sus hijos; en otras ocasiones, son los menores los que entran en contacto con los tratantes en busca de

\footnotetext{
${ }^{21}$ LÓPEZ RODRÍGUEZ, J. (2016, p. 60).

22 Gómez FernándeZ, I. y PÉrez GonZÁlez, C. (2015, p. 229).

${ }^{23}$ Téngase en consideración ORGANIZACIÓN INTERNACIONAL DEL TRABAJO (2009, pp. 27-28).

${ }^{24}$ Daunis Rodríguez, A. (2013, p. 82); Pérez Cepeda, A.I. (2004, p. 35); y Villacampa Estiarte, C. (2011a, p. 38 ).

${ }^{25}$ SCARPA, S. (2008, p. 17)

${ }^{26}$ ARONOWITZ, A. (2009, pp. 38-42); BADIA MARTí, A.M. (2010, pp. 119-120); y GÓMEZ ISA, F. (2000, pp. 1519). Sobre la especial vulnerabilidad de los menores frente a la trata en los contextos de desastres naturales, consúltese el apartado B.3 del Report of the Special Rapporteur on the sale of children, child prostitution and child pornography, Najat Maalla M'jid, presentado en el Consejo de Derechos Humanos de las Naciones Unidas en su decimonovena sesión.
} 
unas mejores condiciones de vida; también es habitual la ficción de una relación sentimental para captar a la víctima menor de edad; en algunos lugares, los menores son captados mediante el empleo de rituales religiosos (como, por ejemplo, el vudú); los menores de corta edad pueden convertirse en víctimas de trata junto con sus padres o familiares; $\mathrm{o}$, incluso, los tratantes pueden utilizar la fuerza y la violencia para captar y reclutar a los menores. En los últimos años, se ha detectado el uso de las nuevas tecnologías de la información y de la comunicación, sobre todo de Internet, como mecanismo rápido, fácil y anónimo para captar a los menores de edad con fines de explotación ${ }^{27}$.

Después de efectuarse la captación, se produce el traslado de las víctimas a otro lugar. A través de este cambio de ubicación, que los menores realizan solos o acompañados por los tratantes, se aleja a los menores de su entorno y, consecuentemente, se acentúa aún más su vulnerabilidad. En concreto, este desplazamiento puede realizarse bien de un lugar a otro dentro del mismo Estado (trata de menores interna), bien de un Estado a otro (trata de menores internacional) ${ }^{28}$. En este último supuesto, el cruce de fronteras puede efectuarse tanto por vías legales como ilegales. Asimismo, el traslado puede llevarse a cabo indistintamente por tierra, mar o aire, y pueden emplearse medios de transporte públicos o privados; incluso, el traslado (o, por lo menos, parte del mismo) puede llegar a realizarse a pie. En ciertas ocasiones, además, se emplean transportes no seguros y de escasa calidad que ponen en peligro la vida y la seguridad de los menores.

Una vez en el lugar de destino, los menores son recibidos y alojados. En este momento, puede ser que la misma persona que ha llevado a cabo la captación y/o el traslado se encargue también de su alojamiento o, por el contrario, pueden intervenir terceras personas. Realmente, la forma en la que se produce la recepción variará de un supuesto a otro, al igual que lo hará el alojamiento. En este contexto, los menores suelen encontrarse desorientados; no cuentan con apoyo social o familiar; $y$, a veces, son sometidos a situaciones de violencia.

Por otro lado, en relación con el segundo de los elementos, cabe señalar que la acción característica de la trata de menores debe desarrollarse con una finalidad concreta, esto es, con la intención de explotar a la víctima. A este respecto, debe matizarse que la realización de la acción descrita con el fin de explotar a la víctima menor de edad es suficiente para calificar un supuesto como trata de menores. Precisamente, la trata constituye un delito instrumental que no engloba la fase de explotación ${ }^{29}$. En este sentido, si finalmente llega a materializarse la explotación, el

\footnotetext{
${ }^{27}$ SYKIOTOU, A.P. (2007, pp. 21-23). Asimismo, vid. ARRIETA IDIAKEZ, F.J., MANRIQUe LóPeZ, F. y MANRIQUE RoJo, F. (2011, p. 299).

${ }^{28}$ Mier Hernández, A. y RodríGuez-Argüelles, S. (2011, p. 197).

${ }^{29}$ LÓPEZ RODRÍGUEZ, J. (2016, p. 62).
} 
delito de trata de menores concurrirá con el delito de explotación correspondiente, esto es, habrá dos delitos diferentes, lo que tendrá relevancia a efectos de pena.

Para delimitar el alcance de este segundo elemento, debe comprobarse cuál es el significado del término «explotación». Pues bien, ninguno de los tres instrumentos jurídicos mencionados define esta palabra, limitándose a enumerar, en su defecto, una serie de prácticas como formas de explotación del ser humano a las que puede conducir la trata.

En concreto, el Protocolo de Palermo determina que la explotación incluirá, como mínimo, «la explotación de la prostitución ajena u otras formas de explotación sexual, los trabajos o servicios forzados, la esclavitud o las prácticas análogas a la esclavitud, la servidumbre o la extracción de órganos» ${ }^{30} ;$ por su parte, el Convenio de Varsovia dispone que la explotación implicará, como mínimo, «la explotación de la prostitución de otras personas $u$ otras formas de explotación sexual, el trabajo o los servicios forzados, la esclavitud o las prácticas análogas a la esclavitud, la servidumbre o la extirpación de órganos» ${ }^{31}$; y la Directiva 2011/36/UE establece que la finalidad de explotación abarcará, como mínimo, «la explotación de la prostitución ajena, u otras formas de explotación sexual, el trabajo o los servicios forzados, incluida la mendicidad, la esclavitud o prácticas similares a la esclavitud, la servidumbre, la explotación para realizar actividades delictivas o la extracción de órganos» ${ }^{32}$, mencionando también como posibles fines de la trata «la adopción ilegal o los matrimonios forzados» ${ }^{33}$. El empleo de la expresión «como mínimo» denota que las enumeraciones incluidas en los instrumentos tienen un carácter abierto y que, por consiguiente, se admiten otras formas de explotación de los seres humanos como finalidades de la trata.

En suma, cabe concluir que estos instrumentos incorporan una regulación de mínimos sobre el concepto de explotación que permite considerar como formas de explotación otras distintas a las mencionadas de manera expresa. En consecuencia, la explotación que se persigue en la trata de menores puede ser de lo más heterogénea y diversa.

\section{La trata de menores de edad en los instrumentos legales internacionales}

\subsection{Primeras iniciativas}

\footnotetext{
${ }^{30}$ Artí́culo 3.a).

${ }^{31}$ Artículo 4.a).

${ }^{32}$ Artículo 2.3.

${ }^{33}$ Considerando 11.
} 
La preocupación de la comunidad internacional por la trata de personas, en general, y por la trata de menores, en particular, nace a comienzos del siglo XX, cuando el discurso de los Derechos Humanos se fue asentado progresivamente a nivel mundial ${ }^{34}$.

El primer documento internacional que muestra preocupación por este fenómeno es el Acuerdo internacional para la represión de la trata de blancas ( 18 de mayo de 1904) $)^{35}$, adoptado en el seno de la Sociedad de Naciones. El Acuerdo se centraba únicamente en la trata de mujeres mayores o menores de edad cuando la finalidad fuera la explotación sexual. No obstante, las obligaciones que imponía ese instrumento distan mucho de las que aparecen en los documentos más actuales, y de hecho, el Acuerdo es criticado por el objetivo que pretendía, no tanto relacionado con la protección de los derechos humanos, sino con una "moral pública" conforme a los estándares europeos ${ }^{36}$.

Sólo unos años después, en la misma organización internacional se adoptaba la Convención internacional para la represión de la trata de blancas ( 4 de mayo de 1910) ${ }^{37}$, que pretendía castigar a quien, incluso con su consentimiento, «ha procurado, persuadido o conducido» a fines inmorales a una mujer menor de edad, aun cuando las conductas se hubieran llevado a cabo en diversos países ${ }^{38}$. Asimismo, debía castigarse también a quien realizara esas mismas conductas sobre mujer mayor de edad cuando empleara fraude, violencia, amenazas, abuso de autoridad u otro medio de sujeción, aunque hubieran acontecido en diversos países ${ }^{39}$. Nótese que ya desde este momento se distingue la trata de adultos de la trata de menores, puesto que en el segundo supuesto no es precisa la concurrencia de unos medios determinados para la captación, como actualmente reconocen los instrumentos supranacionales más relevantes. Igualmente, en esta Convención se aprecia que no es necesario el carácter transnacional para afirmar la existencia de trata.

La preocupación por esta lacra en las primeras décadas del siglo $\mathrm{XX}$, como se ha señalado, era evidente. De ahí que la comunidad internacional continuara elaborando instrumentos internacionales encaminados a lograr su erradicación. El 30 de septiembre de 1921, la Sociedad de Naciones adoptaba un nuevo texto en cuyo intitulado ya se hace referencia expresa a la trata de menores: la Convención internacional para la

\footnotetext{
${ }^{34}$ BOLdOVA PASAMAR, M.A., et al (2010, pp. 54-55).

${ }^{35}$ Enmendado por el Protocolo hecho en Lake Success, Nueva York, el 4 de mayo de 1949. Entró en vigor el 18 de julio de 1905 .

${ }^{36}$ Boldova PASAMAR, M.A., et al (2010, p. 55).

${ }^{37}$ Enmendada por el Protocolo hecho en Lake Success, Nueva York de 4 de mayo de 1949. Entró en vigor el 21 de junio de 1951.

${ }^{38}$ Artículo 1.

${ }^{39}$ Artí́culo 2.
} 
represión de la trata de mujeres y menores. Su artículo 2 insta a la persecución y castigo de los responsables de la trata de menores (ya de ambos sexos) y su artículo 7 exige la adopción de medidas destinadas a prevenir la trata de mujeres y menores, como por ejemplo, protegerlos cuando «viajen a bordo de buques para emigrantes, no sólo a la salida y a la llegada, sino durante la travesía» y «tomar las providencias a afecto de que se coloquen en lugares visibles, en las estaciones y en los puertos, avisos en que se prevenga a las mujeres y a los menores contra los peligros de la trata, y en los que señalen los lugares donde pueden hallar alojamiento y ayuda».

El 11 de octubre de 1933 se adoptaba, de nuevo en el marco de la Sociedad de Naciones, una nueva convención sobre la trata, si bien, referida en exclusiva a mujeres adultas, la Convención internacional relativa a la represión de la trata de mujeres mayores de edad ${ }^{40}$, con el que se pretendía perfeccionar los documentos anteriores.

Ya bajo los auspicios de la Organización de Naciones Unidas se adoptaba el 2 de diciembre de 1949, la Convención para la represión de la trata de personas y de la explotación de la prostitución ajena ${ }^{41}$, un documento que mezcla ambos conceptos prohibiendo una y otra conducta en tanto que son «incompatibles con la dignidad y el valor de la persona humana y ponen en peligro el bienestar del individuo, de la familia y de la comunidad», según señala su Preámbulo. Como los instrumentos anteriores, éste se centra únicamente en la trata con fines de explotación sexual, aunque reconociendo que la trata podía afectar a personas de ambos sexos. Exige a los Estados partes al castigo de la trata y de la explotación de la prostitución, así como de la tentativa y la participación en estas conductas ${ }^{42}$, la protección de las víctimas de esas conductas ${ }^{43}$, la prevención de las mismas ${ }^{44}$ y la cooperación internacional (ej. extradición) ${ }^{45}$; cuatro piezas clave para luchar contra la trata de seres humanos que aparecen también en los documentos más recientes.

La Organización de Naciones Unidas adoptaba el 7 de septiembre de 1956 la Convención suplementaria sobre la abolición de la esclavitud, la trata de esclavos y las instituciones y prácticas análogas a la esclavitud ${ }^{46}$, cuyo artículo 1.d insta a los Estados partes a abolir toda práctica en virtud de la cual un menor es entregado por

\footnotetext{
${ }^{40}$ Entró en vigor el 21 de junio de 1938.

${ }^{41}$ Entró en vigor el 25 de julio de 1951.

${ }^{42}$ Artículos 1 a 4 .

${ }^{43}$ Artículos 18 y 19.

${ }^{44}$ Artículos 17 y 20; este último referido expresamente a los menores. Artículo 20 de la Convención para la represión de la trata de personas y de la explotación de la prostitución ajena: "Las Partes (...) deberán adoptar la medidas necesarias para la inspección de las agencias de colocación, a fin de impedir que las personas que buscan trabajo, en especial las mujeres y los niños, se expongan al peligro de la prostitución."

${ }^{45}$ Artículos 8 y 9.

${ }^{46}$ Entró en vigor el 30 de abril de 1957.
} 
sus padres o tutores a otra persona, mediante remuneración o sin ella, con el fin de explotación.

El 20 de noviembre de 1959 veía la luz, de nuevo en el seno de la misma organización, aunque sin carácter vinculante, la Declaración de los derechos del niño ${ }^{47}$, germen de la convención que vería la luz tres décadas después. El principio IX de la Declaración, sobre la base de un documento anterior adoptado por la Sociedad de Naciones (Declaración de Ginebra sobre los derechos del niño, 1924), exige proteger a los menores contra toda forma de abandono, crueldad y explotación, no debiendo ser éste sometido a ningún tipo de trata.

El instrumento que marca un hito en la lucha por los derechos de los menores es, sin duda, su convención de 1989 , la Convención sobre los derechos del niño ${ }^{48}$. Esta Convención no se olvida de la trata, en tanto que es una conducta que lesiona los derechos más básicos de cualquier ser humano, y en especial, de los niños, niñas y adolescentes. Si bien, las referencias a la trata a lo largo del articulado son pocas y muy generales dado que la convención aborda otros muchos aspectos relacionados con los derechos del niño. Los artículos 34, 35, 36 y 39 son especialmente importantes en el ámbito que nos ocupa en este trabajo. El primero de ellos insta a los Estados partes a proteger al niño frente a toda forma de explotación y abuso sexuales. El segundo les obliga a adoptar las medidas necesarias para impedir el secuestro, la venta o la trata de niños con cualquier fin o en cualquier forma. Esta disposición evidencia que la finalidad de la trata de menores no se circunscribe a la intención de explotar sexualmente a la víctima ${ }^{49}$. El tercero de los artículos mencionados les demanda proteger al niño contra todas las demás formas de explotación que sean perjudiciales para cualquier aspecto de su bienestar. Y el artículo 39, por su parte, aborda un aspecto de crucial importancia: la protección de las víctimas. Así, el precepto exige la adopción de «medidas apropiadas para promover la recuperación física y psicológica y la reintegración social de todo niño víctima de cualquier forma de abandono, explotación o abuso, tortura u otra forma de tratos o penas crueles, inhumanos o degradantes, o conflictos armados». Resulta oportuno destacar que es el primer instrumento internacional que hace mención a esta necesidad, a la que instrumentos posteriores prestarán más atención y desarrollarán con más detalle.

\subsection{La Convención interamericana sobre el tráfico internacional de menores}

En los últimos años del pasado milenio, y en un ámbito regional muy concreto donde el problema de la trata era mayor aún que en otras zonas del planeta, se adoptó

\footnotetext{
${ }^{47}$ Asamblea General de las Naciones Unidas, Resolución 1386 (XIV).

${ }^{48}$ Entró en vigor el 2 de septiembre de 1990.

${ }^{49}$ LÓPEZ RODRíGUEZ, J. (2016, p. 34).
} 
el 18 de marzo de 1994 la Convención interamericana sobre el tráfico internacional de menores ${ }^{50}$. Es el primer instrumento que define la trata de personas de manera semejante a como lo hacen los documentos más recientes.

Así, de acuerdo con esta Convención, el concepto de trata de su artículo 2 englobaría los tres elementos señalados supra. En primer lugar, las acciones de trata, que la Convención entiende como la substracción, el traslado o la retención de un menor con propósitos o medios ilícitos, así como la tentativa de estas conductas. En segundo lugar, la finalidad (la Convención utiliza la expresión «propósitos ilícitos»), que incluye la «prostitución, explotación sexual, servidumbre o cualquier otro propósito ilícito, ya sea en el Estado de residencia habitual del menor o en el Estado Parte en el que el menor se halle localizado». En tercer y último lugar, los medios a través de los cuales ha de llevarse a cabo la conducta de trata. A los efectos de la Convención, estos medios incluyen, entre otros, el «secuestro, consentimiento fraudulento o forzado, la entrega o recepción de pagos o beneficios ilícitos con el fin de lograr el consentimiento de los padres, las personas o la institución a cuyo cargo se halla el menor, o cualquier otro medio ilícito ya sea en el Estado de residencia habitual del menor o en el Estado Parte en el que el menor se encuentre».

Respecto de este tercer elemento debe realizarse un comentario esencial. Precisamente, la Convención interamericana lo incluye como necesario para poder hablar de trata de menores, mientras que los instrumentos internacionales posteriores, con acierto, no consideran necesaria su presencia cuando las víctimas son menores, debiéndose constatar esos medios únicamente cuando la víctima es mayor de edad. Como ya se ha mencionado previamente, ello es así porque los menores son mucho más vulnerables a las conductas de trata y su posición (dependencia, sometimiento) respecto de otras personas puede acarrear que no sea necesario emplear con ellos ningún tipo de medio violento o fraudulento para convertirles en víctimas de trata.

La Convención interamericana exige a los Estados partes castigar la trata severamente y con sanciones penales ${ }^{51}$, a la vez que les demanda la adopción de medidas sobre asistencia mutua y extradición que faciliten la persecución y castigo de los responsables de trata ${ }^{52}$. Tímidamente, también insta a los Estados partes a adoptar medidas eficaces para la prevención de la trata de menores, aunque no se

\footnotetext{
${ }^{50}$ Entró en vigor el 15 de agosto de 1997. Sobre este documento es preciso realizar una aclaración previa. Como se observa, su intitulado utiliza el vocablo "tráfico", no "trata", quizá por la influencia del término inglés "trafficking", empleado para describir las conductas objeto de estudio de este trabajo. No obstante, en castellano, el término inglés "trafficking" -en este contexto- debe ser traducido como "trata", mientras que "tráfico" debe emplearse en el sentido del término inglés "smuggling", referidos a los migrantes.

${ }^{51}$ Artículo 7.

${ }^{52}$ Artículos 8 a 10.
} 
pronuncia acerca de medidas concretas ${ }^{53}$. Por último, recoge una serie de medidas destinadas a favorecer la localización y restitución de los menores víctimas de trata ${ }^{54}$.

\subsection{Iniciativas en el marco de la Organización Internacional del Trabajo}

La Organización Internacional del Trabajo, a lo largo de sus casi cien años de historia, ha elaborado diversos documentos, algunos vinculantes y otros de mero soft law, sobre el trabajo de menores. Aquí nos referiremos solamente a uno de ellos, que tiene íntima relación con la trata de menores: el Convenio 182 sobre la prohibición de las peores formas de trabajo infantil y la acción inmediata para su eliminación ${ }^{55}$, de 17 de junio de 1999.

Sin ser un Convenio específico sobre trata, sin duda, se centra en la lucha contra determinadas finalidades de la misma (la explotación laboral y la sexual, y la explotación en la realización de actividades delictivas), instando a los Estados partes a uadoptar medidas inmediatas y eficaces para conseguir la prohibición y la eliminación de las perores formas de trabajo infantil con carácter de urgencia» ${ }^{56}$.

\subsection{Iniciativas recientes en el marco de la Organización de Naciones Unidas}

3.4.1. El Protocolo facultativo a la Convención sobre los derechos del niño relativo a la venta de niños, prostitución infantil y utilización de niños en la pornografía

Como se ha señalado anteriormente, la Convención sobre los derechos del niño de 1989, por su carácter general, no abordaba en profundidad el tema de la trata. De ahí que unos años después, coincidiendo además con una mayor visibilidad de este problema, se adoptara el Protocolo facultativo a la Convención de derechos del niño relativo a la venta de niños, prostitución infantil y utilización de niños en la pornografía 57 , el 25 de mayo de 2000. El articulado del Protocolo no menciona expresamente el término «trata» aunque sí toda una serie de conductas que dan lugar a ella. Así, su artículo 3 exige a los Estados partes adoptar medidas penales respecto de las conductas que a continuación se enumeran, tanto si se han cometido dentro o fuera de sus fronteras, o si se han perpetrado individual o colectivamente:

\footnotetext{
53 De hecho, la mención a la prevención se hace en el artículo 7, ubicado en el Capítulo II dedicado a los aspectos penales.

${ }^{54}$ Artículos 12 a 22.

${ }^{55}$ Entró en vigor el 19 de noviembre de 2000.

${ }^{56}$ Artículo 1.

${ }^{57}$ En vigor desde el 18 de enero de 2002.
} 
a) En relación con la venta de niños, en el sentido en que se define en el artículo $2^{58}$ :

i) Ofrecer, entregar o aceptar, por cualquier medio, un niño con fines de:

a. Explotación sexual del niño;

b. Transferencia con fines de lucro de órganos del niño;

c. Trabajo forzoso del niño;

ii) Inducir indebidamente, en calidad de intermediario, a alguien a que preste su consentimiento para la adopción de un niño en violación de los instrumentos jurídicos internacionales aplicables en materia de adopción;

b) Ofrecer, obtener, facilitar o proporcionar un niño con fines de prostitución, en el sentido en que se define en el artículo 2;

c) Producir, distribuir, divulgar, importar, exportar, ofrecer, vender o poseer, con los fines antes señalados, material pornográfico en que se utilicen niños, en el sentido en que se define en el artículo 2 (...).

Además, exige el castigo de la tentativa, los actos preparatorios y la complicidad ${ }^{59}$.

A los efectos del presente trabajo, debe destacarse que el Protocolo es pionero en diversas cuestiones. Así, es el primer instrumento internacional en el que se menciona expresamente, dentro de los fines de la trata, la transferencia de órganos con fines de lucro. Igualmente, es el primero que habla expresamente de las penas a imponer a los responsables de estos delitos, aunque se limite a señalar que habrán de castigarse con "penas adecuadas a su gravedad» ${ }^{60}$, sin profundizar más. Exige también a los Estados la adopción de las medidas necesarias para hacer efectiva la responsabilidad de personas jurídicas por los delitos mencionados anteriormente ${ }^{61}$. Nótese, además, que no es preciso que las conductas se realicen en diversos Estados.

Sin duda, uno de los grandes avances del Protocolo en la lucha contra la trata de menores tiene que ver con la importancia que otorga a la protección de las víctimas,

\footnotetext{
${ }^{58}$ Artículo 2. A los efectos del presente Protocolo:
}

a) Por venta de niños se entiende todo acto o transacción en virtud del cual un niño es transferido por una persona o grupo de personas a otra a cambio de remuneración o de cualquier otra retribución;

b) Por prostitución infantil se entiende la utilización de un niño en actividades sexuales a cambio de remuneración o de cualquier otra retribución;

c) Por utilización de niños en la pornografía se entiende toda representación, por cualquier medio, de un niño dedicado a actividades sexuales explícitas, reales o simuladas, o toda representación de las partes genitales de un niño con fines primordialmente sexuales.

\footnotetext{
${ }^{59}$ Artículo 3.2.

${ }^{60}$ Artículo 3.3.

${ }^{61}$ Artículo 3.4.
} 
aunque parece centrarse únicamente en su protección durante el proceso penal, olvidándose de momentos previos y posteriores al mismo. Por lo que respecta al proceso, el artículo 8 insta a los Estados a adaptar los procedimientos a las necesidades especiales de niños, niñas y adolescentes, incluidas sus necesidades como testigos; a proteger su identidad e intimidad, a evitar demoras, a formar de manera específica a las personas que van a ejercer labores jurídicas y psicológicas, etc.

El artículo $g$ hace referencia a las medidas de prevención, destacando la necesidad de promover campañas de sensibilización social. Éste mismo aboga, además, por la adopción de medidas para proporcionar una asistencia apropiada a los menores víctimas de estos delitos con el fin de lograr su plena reintegración social y su plena recuperación física y psicológica.

Consciente del carácter internacional que en numerosas ocasiones tienen los delitos señalados en el artículo 3, el Protocolo demanda a los Estados el fortalecimiento de la cooperación internacional para prevenir, detectar, investigar, enjuiciar y castigar a los responsables. Asimismo, la cooperación internacional habrá de ser esencial para acabar con los principales factores que favorecen la vulnerabilidad de los menores y su victimización, como son la pobreza y el subdesarrollo.

3.4.2. Protocolo para prevenir, reprimir y sancionar la trata de personas, especialmente mujeres y niños

En diciembre del año 2000 se abría a la firma en Palermo la Convención de las Naciones Unidas contra la Delincuencia Organizada Transnacional $^{62}$ con el propósito de «promover la cooperación para prevenir y combatir más eficazmente la delincuencia organizada transnacional» ${ }^{63}$. Esta Convención exige a los Estados partes castigar como delito la participación en un grupo delictivo organizado ${ }^{64}$, así como otras conductas íntimamente vinculadas al crimen organizado, tales como: el blanqueo de capitales ${ }^{65}$, la corrupción ${ }^{66}$ y la obstrucción a la justicia ${ }^{67}$. La Convención no hace referencia, sin embargo, a otros delitos concretos que pueden cometer los grupos delictivos organizados, como el tráfico de armas, el tráfico de drogas, el tráfico ilícito de migrantes y la trata de personas. Es por eso que la misma organización internacional adoptó a la vez que la Convención dos Protocolos dedicados a las dos

\footnotetext{
${ }^{62}$ Adoptada por la Asamblea General de las Naciones Unidas el 15 de noviembre de 2000. Entró en vigor el 29 de septiembre de 2003 .

${ }^{63}$ Artículo 1.

${ }^{64}$ Artículo 5 .

${ }^{65}$ Artículo 6.

${ }^{66}$ Artículo 8.

${ }^{67}$ Artículo 23.
} 
últimas tipologías delictivas ${ }^{68}$ : el Protocolo para prevenir, reprimir y sancionar la trata de personas, especialmente mujeres y niños, que complementa la Convención de las Naciones contra la Delincuencia Organizada Transnacional y el Protocolo contra el tráfico ilícito de migrantes por tierra, mar y aire, que complementa la Convención de las Naciones Unidas contra la Delincuencia Organizada Transnacional.

El primero de ellos, al que ya nos hemos venido refiriendo a lo largo de este trabajo como Protocolo de Palermo, marca, sin duda, un antes y un después en la lucha contra la trata de personas. Se trata, por el momento, del único instrumento con carácter verdaderamente universal, puesto que el resto proceden de organizaciones regionales. En su momento fue, además, el documento más avanzado, aunque desde su adopción se observaron carencias que serían superadas por instrumentos regionales posteriores. Entre esas carencias, hay que destacar, en un trabajo como éste dedicado al estudio de la trata de menores, que pese a que su intitulado hace referencia expresa a los «niños», apenas les presta atención en su articulado, siendo escasas las referencias a éstos.

Con todo, el Protocolo de Palermo ofrece por primera vez en el panorama internacional una definición de trata de menores. Tal y como se ha expuesto supra, esta definición parte de la definición general de trata, que abarca tres elementos principales (acción, medios y finalidad), pero puntualiza que cuando las conductas impliquen a menores de edad (definidos como los menores de dieciocho años), se considerará que hay trata con independencia de que se hayan empleado o no los medios.

Las medidas que recoge el Protocolo para combatir la trata pueden agruparse en cuatro grandes bloques: criminalización, prevención, protección y cooperación internacional. Comentar todos ellos en profundidad excedería los límites razonables de un trabajo de este tipo, por lo que nos centraremos exclusivamente en las cuestiones más relevantes y en las relacionadas con los menores.

Así, en el ámbito de la criminalización, el Protocolo no prevé como circunstancia agravante del delito de trata el hecho de que la víctima sea menor de edad ${ }^{69}$. Además, el ámbito de aplicación del Protocolo es muy limitado en este punto dado que, de acuerdo con su artículo 4, sólo se aplicará a la prevención, investigación y penalización de los delitos de trata cuando éstos tengan «carácter transnacional y entrañen la

\footnotetext{
${ }^{68}$ Un año después se adoptó un protocolo en materia de tráfico de armas: el Protocolo contra la fabricación y tráfico ilícitos de armas de fuego, sus piezas y componentes y municiones, que complementa la Convención de las Naciones Unidas contra la Delincuencias Organizada Transnacional, de 31 de mayo de 2001. Sobre drogas, desde 1988 existe la famosa Convención de las Naciones Unidas contra el tráfico ilícito de estupefacientes y sustancias psicotrópicas (Convención de Viena).

${ }^{69}$ Cuestión que no es extraña en otros documentos de Naciones Unidas. Así, el emplear a un menor de edad para cometer un delito de tráfico de drogas está previsto como circunstancia agravante en la ya referida Convención de Viena.
} 
participación de un grupo delictivo organizado» ${ }^{70}$. Dos elementos, éstos, que la doctrina no considera necesarios pues si bien pueden estar presentes, y de hecho, en numerosos casos lo están, no son imprescindibles para que se dé la conducta de trata $^{71}$.

El Protocolo merece ser criticado, además, por centrarse en exclusiva en la criminalización de la trata, prestando escasa atención a las medidas de prevención y de protección de las víctimas y potenciales víctimas. Estas lagunas jurídicas ponen de manifiesto que este instrumento no fue elaborado para definir y regular los derechos humanos de las víctimas de la trata, sino que fue redactado para «tipificar a nivel universal un conjunto de conductas estrechamente vinculadas al crimen organizado transnacional que, por su expansión y gravedad, habían alcanzado el mismo nivel de preocupación en la Comunidad Internacional que el tráfico ilícito de drogas y estupefacientes, el tráfico ilegal de armas, el blanqueo de capitales o el terrorismo internacionalı $>2$.

En lo que respecta a las medidas de prevención, el Protocolo contiene un breve listado de medidas que son, además, excesivamente vagas. Entre estas medidas está la necesidad de lanzar campañas de concienciación para desalentar la demanda de toda forma de explotación y para reducir los factores que favorecen la victimización, como la pobreza, el subdesarrollo y la desigualdad. Es en este punto donde se encuentra la única referencia expresa a menores, abogando el Protocolo por la necesidad de reducir el riesgo de que éstos se conviertan en víctimas. Sin embargo, no concreta ninguna medida. Ignora, además, que las campañas de concienciación han de ser diferentes en función de quien sea el destinatario de la misma, pues no es suficiente con lanzar campañas a la población en general, sino que deben lanzarse específicamente a víctimas o potenciales víctimas, a personas con probabilidad de entrar en contacto con víctimas o potenciales víctimas (abogados, fiscales, jueces, policías, trabajadores sociales, etc.) y a los demandantes de los servicios ofrecidos por las víctimas de trata ${ }^{73}$.

De igual manera debe criticarse, en el ámbito de la protección de las víctimas y potenciales víctimas, en primer lugar, el modo en que las medidas de protección están

\footnotetext{
$7^{70}$ El concepto de grupo delictivo organizado debe entenderse en el sentido de la definición contenida en la Convención de las Naciones Unidas contra la delincuencia organizada transnacional (artículo 5).

${ }^{71}$ Vid., entre otros, Mier Hernández, A. y RodrígueZ-Argüelles. S. (2011, p. 197); SCARPA, S. (2008, p. 5); y VILLACAMPA ESTIARTE, C. (2011a, p. 39)

${ }^{72}$ Circular 5/2011 sobre criterios para la unidad de actuación especializada del Ministerio Fiscal en materia de extranjería e inmigración, p. 1549.

73 Sobre la necesidad de establecer diversos grupos de destinatarios de estas conductas, vid. ampliamente, PÉrez CePedA, A.I. y Benito SÁnCHEZ, D. (2014, pp. 26-28).
} 
redactadas $^{74}$. Ciertamente, en comparación con la naturaleza imperativa de las disposiciones punitivas, la redacción de las disposiciones relativas a la protección de las víctimas da a entender que se trata de disposiciones de «naturaleza facultativa» ${ }^{75}$, esto es, mero soft law que los Estados parte pueden decidir si aplicar o no ${ }^{76}$. En segundo lugar, es decepcionante el olvido de ciertas medidas de protección que se consideran esenciales para luchar contra la trata, como es la concesión de un período de reflexión y recuperación y de un permiso de residencia. Tampoco se establecen medidas relativas a la identificación de víctimas o potenciales víctimas de trata, lo que es uno de los principales retos en el momento actual para combatir este fenómeno, más aún cuando las víctimas son menores.

En suma, debe concluirse que el enfoque adoptado por el Protocolo de Palermo es preeminentemente criminalista y que no aborda la trata como una cuestión de derechos humanos ${ }^{77}$. No obstante todas las carencias y críticas mencionadas, debe tenerse en cuenta el impulso que supuso el Protocolo de Palermo en la lucha contra esta lacra en el contexto de las sociedades actuales. Además, es preciso señalar que algunas de sus lagunas han sido colmadas por los instrumentos legales adoptados en el ámbito europeo que a continuación se analizan.

\subsection{La Convención para la prevención y combate contra el tráfico de mujeres y niños para la prostitución}

Como se ha referido en la introducción de este trabajo, la trata de menores es un problema aún mayor en determinadas zonas del planeta, a saber, África, Oriente Medio y Sur Este Asiático, de ahí que existan iniciativas específicas para combatir este fenómeno en dichas zonas.

Así, en el marco de la Asociación Regional de Cooperación del Sur de Asia (SAARC, por sus siglas en inglés) se adoptó el 5 de enero de 2002 la Convención para la Prevención y Combate contra el Tráfico de Mujeres y Niños para la Prostitución ${ }^{78}$. Esta Convención se dirige en exclusiva a prevenir el uso de mujeres y niños en las redes de prostitución internacionales. Su definición del fenómeno trata incluye también los tres elementos básicos (acción, finalidad y medios), si bien el contenido de cada uno de ellos es más limitado que el del Protocolo de Palermo ${ }^{79}$. Así, entre las acciones incluye

\footnotetext{
${ }^{74}$ El texto utiliza expresiones como "Cuando proceda y en la medida que lo permita su derecho interno, cada Estado Parte (...)","Cada Estado Parte considerará la posibilidad (...)", "Cada Estado Parte se esforzará por prever (...)".

75 GALLAGHER, A.T. (2001, p. 990).

${ }^{76}$ Destacándolo, PÉrez GonZÁLEZ, C. (2014, p. 72).

77 En este sentido, véanse LARA AGUAdo, A. (2012, pp. 67-68) y RodríGUEZ-PIÑERo y BRAVo-FERRER, M. (2011, p. 15).

${ }^{78}$ Entró en vigor el 1 de diciembre de 2005.

${ }^{79}$ GALLAGHeR, A. (2010, p. 43).
} 
solamente el traslado, la compra o la venta de mujeres o niños para la prostitución ${ }^{80}$, olvidándose de otras conductas como la transferencia y la recepción. Entre los medios no se incluye el abuso de poder o de una posición de vulnerabilidad, ni la concesión o recepción de pagos o beneficios para lograr el consentimiento de una persona que tiene control sobre otra. Por lo que respecta a las finalidades, como su título indica, se limita a la explotación sexual.

La trata, así definida, tendrá que ser tipificada como delito por los Estados partes, así como la tentativa y la complicidad ${ }^{81}$ y el hecho de que la víctima sea un menor de edad tendrá que ser considerado una circunstancia agravante de la pena ${ }^{82}$.

\subsection{El Convenio del Consejo de Europa sobre la lucha contra la trata de seres humanos}

Como se ha señalado en el epígrafe anterior, algunas de las carencias del Protocolo de Palermo han sido superadas por otros instrumentos legales posteriores, si bien, reducidos a un ámbito regional concreto, el europeo: bien en el marco del Consejo de Europa, bien en el marco de la Unión Europea.

El Consejo de Europa comenzó a trabajar en la lucha contra la trata de seres humanos a comienzos de los noventa ${ }^{83}$, cuando otras organizaciones supranacionales e internacionales apenas prestaban atención a este fenómeno. Sin embargo, todas esas iniciativas se centraban básicamente en la trata de mujeres con fines de explotación sexual ${ }^{84}$. Por ello, el Alto Comisionado para los Derechos Humanos instó al Consejo de Europa a que su Convención siguiera la línea empezada en Palermo, y no se centrara únicamente en ese aspecto de la trata. Así, se estableció un Comité ad hoc sobre acción contra la trata de seres humanos que redactó un borrador de Convención que se aprobó el 16 de mayo de 2005 en Varsovia, el Convenio del Consejo de Europa sobre la lucha contra la trata de seres humanos.

En efecto, este instrumento continúa la labor de las Naciones Unidas al adoptar el Protocolo de Palermo y la mejora. Parte de la misma definición de trata pero incorpora algunas novedades que tienen en cuenta la realidad del fenómeno. Así, el Convenio del Consejo de Europa «se aplicará a todas las formas de trata de seres humanos, nacionales o transnacionales, relacionadas o no con la delincuencia

\footnotetext{
${ }^{80}$ Artículo 1.3.

${ }^{81}$ Artí́culo 3.

${ }^{82}$ Artículo 4.1.e)

${ }^{83}$ Para una descripción detallada de los trabajos del Consejo de Europa en materia de trata, vid. GALLAGHER, A. (2006, pp. 170-173).

${ }^{84}$ Recomendación 1325 (1997) relativa a la trata de mujeres y a la prostitución forzosa en los Estados miembros del Consejo de Europa; Recomendación 1450 (2000) sobre la violencia contra las mujeres en Europa; Recomendación 1545 (2002) campaña contra la trata de mujeres; Recomendación 1610 (2003) migraciones relacionadas con la trata de mujeres y la prostitución.
} 
organizada» $^{85}$. La trata aparece ahora, de manera acertada, como un fenómeno que no tiene por qué tener carácter transnacional ni vínculos con el crimen organizado.

Otras novedades del Convenio de Varsovia son, por un lado, la incorporación de un mecanismo de seguimiento, el llamado GRETA (Group of Experts on Action against Trafficking in Human Beings) ${ }^{86}$, encargado de velar por la aplicación del Convenio, y por otro, la inclusión de la perspectiva de género en la lucha contra estas prácticas ${ }^{87}$. A este último respecto, la perspectiva de género «se presenta como fundamental para poder analizar las diversas dimensiones de la trata, y sus efectos diferenciales en las formas y efectos de la misma en las personas afectadas» ${ }^{88}$.

Sin duda, lo más relevante de este documento supranacional es el cambio de paradigma que adopta la lucha contra la trata de seres humanos, de una perspectiva meramente punitivista a otra centrada en la protección de los derechos humanos de las víctimas y potenciales víctimas, donde la protección de éstas se convierte en esencial frente a la-también importante-criminalización ${ }^{89}$. En este sentido, tal y como se expresa en el Preámbulo, el Convenio incorpora un enfoque de género y un enfoque respetuoso con los derechos de los menores de edad ${ }^{90}$.

Centrándonos en esto último, por ser el objeto de estudio de este trabajo, es preciso señalar que son diversas las referencias a los menores en el articulado del Convenio. En el ámbito de la criminalización -siguiendo la línea del Protocolo de Palermo-, no exige la utilización de medios específicos cuando las víctimas son menores de edad; además, requiere a los Estados que prevean como circunstancia agravante de la pena el hecho de que la conducta recaiga sobre un menor, aunque no establece marcos penales concretos, limitándose a señalar que las penas habrán de ser efectivas, proporcionadas y disuasorias, e incluyan penas privativas de libertad que puedan dar lugar a la extradición.

En el ámbito de la prevención, el Convenio hace hincapié en la necesidad de adoptar medidas específicas para reducir la vulnerabilidad de los menores ante la trata, creando un entorno protector para ellos ${ }^{91}$.

Pero es sin duda en el ámbito de la protección donde más medidas específicas respecto de menores se encuentran, como a continuación se indica.

\footnotetext{
${ }^{85}$ Artículo 2.

86 Artículo 36.1 Los informes están disponibles en http://www.coe.int/t/dghl/monitoring/trafficking/docs/monitoring/GRETA_en.asp (última consulta el 9/10/2018).

${ }^{87}$ Artículo 17. Sobre la inclusión de la perspectiva de género, puede consultarse ORBEGOzO ORONOZ, I. (2013, p. 112).

${ }^{88}$ GARCÍA CUESTA, S. (2012, p. 59).

${ }^{89}$ VILLACAMPA ESTIARTE, C. (2011b, p. 12).

${ }^{90}$ A este respecto, vid. SAX, H. (2018, p. 251).

${ }^{91}$ Artículo 5.5.
} 
- Cuando se desconozca la edad de la víctima pero haya razones para creer que es menor de edad, será considerado como tal y se le concederán medidas específicas de protección hasta la comprobación de su edad ${ }^{92}$.

-A los menores no acompañados y a los que se presuman menores no acompañados se les nombrará un representante que vele por sus intereses, se adoptarán las medidas necesarias para establecer su identidad y nacionalidad y se realizan todos los esfuerzos necesarios para encontrar a su familia cuando se trate del interés superior del menor ${ }^{93}$.

- Las medidas sobre protección de la vida privada y de la identidad de todo tipo de víctimas deberán ir dirigidas, en el caso de los menores, a garantizar que la identidad $\mathrm{u}$ otros elementos que permitan la identificación del menor no se hagan públicos ni en medios de comunicación ni en ningún otro medio, salvo que por circunstancias excepcionales sean necesarias para localizar a su familia ${ }^{94}$.

-La asistencia a víctimas menores de edad deberá incluir, como mínimo, acceso a la educación ${ }^{95}$.

-Los Estados asegurarán que las disposiciones sobre alojamiento, educación y atención sanitaria a menores víctimas de trata tienen en cuenta sus derechos ${ }^{96}$.

-Por lo que respecta al permiso de residencia que debe otorgarse a víctimas de trata, en el caso de menores se expedirá teniendo en cuenta su interés superior $y_{\text {, }}$ en su caso, se renovará en las mismas condiciones ${ }^{97}$.

-Los menores víctimas no serán repatriados a un Estado que, tras la valoración de los riesgos y de la seguridad, se compruebe que el retorno no contribuye al interés superior del menor ${ }^{98}$.

-En el ámbito del proceso penal, los menores han de gozar de medidas de protección especiales que tengan en cuenta su interés superior ${ }^{99}$.

Hay que destacar que las disposiciones relativas a medidas de protección son de obligado cumplimiento en el ámbito del Convenio, a diferencia de lo que sucede en el Protocolo de Palermo. La inclusión de estas medidas para proteger y promover los derechos humanos de las víctimas y potenciales víctimas supone la «intensificación de

\footnotetext{
${ }^{92}$ Artículo 10.3.

93 Artículo 10.4.

${ }^{94}$ Artículo 11.2.

${ }^{95}$ Artículo 12.1.f).

${ }^{96}$ Artículo 12.7.

${ }^{97}$ Artículo 14.2.

${ }^{98}$ artículo 16.7 .

99 artículo 28.3.
} 
la perspectiva victimocéntrica y de derechos humanos escasamente manifestada hasta entonces en los instrumentos internacionales en la materia» ${ }^{100}$.

\subsection{Iniciativas en el marco de la Unión Europea}

La verdadera lucha contra la trata de seres humanos comienza en el ámbito de la Unión Europea a mediados de los años noventa, adoptándose dos acciones comunes: la Acción Común 96/700/JAl, de 29 de noviembre de 1996, por la que se establece un programa de estímulo e intercambios destinado a los responsables de la acción contra la trata de seres humanos y la explotación sexual de los niños ${ }^{101}$, y la Acción Común 97/154/JAl, de 24 de febrero de 1997 relativa a la lucha contra la trata de seres humanos y la explotación sexual de los niños. ${ }^{102}$ Como se observa, esta última aborda específicamente el tema de la trata de menores, si bien, en ese momento todavía no existía consenso sobre el concepto de trata y este fenómeno debía vincularse, en todo caso, con el fenómeno de la inmigración ilegal. Así, la definición de trata que proporcionaba la Acción Común era la siguiente: «cualquier conducta que facilite la entrada, tránsito, residencia o salida del territorio de un Estado miembro para los fines» de explotación sexual.

Con la llegada del nuevo milenio, se lanzó el Programa Daphne ${ }^{103}$, una iniciativa dedicada a prevenir la violencia ejercida sobre niños, adolescentes y mujeres, incluida la trata. En 2002, el Consejo de la Unión Europa adoptó un nuevo instrumento, la Decisión Marco 2002/629/JAI de 19 de julio de 2002, relativa a la lucha contra la trata de seres humanos ${ }^{104}$, germen de la Directiva sobre trata actualmente en vigor. La Decisión Marco del año 2002 parte de la definición del Protocolo de Palermo, aunque sin exigir el elemento de la transnacionalidad ni vínculos con el crimen organizado. En la línea del Protocolo de Palermo, entiende que cuando la trata afecte a menores de dieciocho años, no será necesario el uso de medios específicos. La Decisión Marco, como el Protocolo de Palermo, se centra en la criminalización de los responsables del delito de trata, olvidándose de la prevención y de la protección de las víctimas ${ }^{105}$. Únicamente su artículo 7 hace mención a los menores, indicando que éstos deberán ser considerados «víctimas especialmente vulnerables» a la hora de aplicar la Decisión Marco 2001/220/JAl del Consejo, de 15 de marzo de 2001, relativa al estatuto de la

\footnotetext{
${ }^{100}$ De LA Cuesta ARZAMENDI, J.L. (2013, p. 46).

${ }^{101}$ DOCE $L 322$ de 12 de diciembre de 1996.

${ }^{102}$ DOCE L 63 de 4 de marzo de 1997.

${ }^{103}$ Decisión 293/200o/CE del Parlamento Europeo y del Consejo, de 24 de enero de 2000, por la que se aprueba un programa de acción comunitario sobre medidas preventivas destinadas a combatir la violencia ejercida sobre los niños, los adolescentes y las mujeres (2000-2003) (programa Daphne), DOCE L 34 de 9 de febrero de 2000.

${ }^{104}$ DOCE L203 de 1 de agosto de 2002.

${ }^{105}$ WYLIE, G. Y MCREDMOND, P. (2010, p. 4).
} 
víctima en el proceso penal ${ }^{106}$, y que los Estados miembros adoptarán todas las medidas posibles para que la víctima menor y su familia reciban la asistencia adecuada.

En los años posteriores, la política criminal de la Unión Europea en materia de trata experimentó un cambio crucial. El anterior enfoque punitivista es reemplazado por uno victimocentrista ${ }^{107}$. Sobre la base de esta nueva perspectiva, se adopta el instrumento más reciente contra la trata en la Unión Europea, a saber, la Directiva 2011/36/UE del Parlamento Europeo y del Consejo, de 5 de abril de 2011 relativa a la prevención y lucha contra la trata de seres humanos y a la protección de las víctimas y por la que se sustituye la Decisión Marco 2002/629/JAl del Consejo ${ }^{108}$. Tal y como se especifica en el Considerando 7, la Directiva adopta un enfoque «integrado, global y basado en los derechos humanos» para prevenir y combatir la trata. Debe destacarse que este nuevo instrumento presta especial atención a la prevención del fenómeno y a la protección de las víctimas, a la vez que prevé un número de medidas relativas a la investigación y persecución de este delito que también constituyen una novedad.

La Directiva parte de la definición de trata de los instrumentos de Naciones Unidas y del Consejo de Europa, y añade alguna novedad más. Así, tal y como se ha avanzado supra, entre los fines de la trata incluye expresamente la mendicidad y otras actividades delictivas. Si bien es cierto que estos fines no son exclusivos de la trata de menores, debe matizarse que son muy frecuentes en ella pues los tratantes se aprovechan de la irresponsabilidad penal del menor o de su responsabilidad disminuida para, por ejemplo, cometer delitos o faltas contra el patrimonio (hurtos, robos) o delitos relacionados con el tráfico de drogas ${ }^{109}$. Debe destacarse, asimismo, que la Directiva incluye entre las conductas de trata el intercambio de control sobre una persona.

Por lo que respecta específicamente a los menores, son varias las disposiciones de la Directiva que hacen referencia expresa a ellos. En el ámbito de la criminalización, por ejemplo, se exige sancionar con más pena, esto es, incluir como agravante el hecho de que la víctima sea menor de edad ${ }^{110}$. Es el único documento que señala un marco penal concreto, exigiendo que la pena privativa de libertad tenga en estos casos una duración máxima de al menos diez años.

En lo relativo a la protección, hay que destacar el artículo 13.1, el cual dispone que el «interés superior del menor será una consideración primordial». Para tal fin, la Directiva

\footnotetext{
${ }^{106}$ DOCE L 82 de 22 de marzo de 2001.

${ }^{107}$ VILLACAMPA ESTIARTE, C. (2011b, p. 2).

${ }^{108}$ DOUE L101 de 15 de abril de 2011.

${ }^{109}$ ORGANIZACIÓN INTERNACIONAL DEL TRABAJO (2009, pp. 29-30).

${ }^{110}$ Artículo 4.2.a).
} 
exige una serie de obligaciones a los Estados miembros, entre las que destacan las siguientes:

- La consideración como menor de edad a una víctima de trata de edad incierta pero respecto de la cual haya razones para creer que es efectivamente menor, para que así reciba inmediatamente la asistencia, apoyo y protección necesarias $^{111}$.

-La evaluación individual de las circunstancias específicas de las víctimas menores teniendo en cuenta sus opiniones, necesidades e intereses para adoptar las medidas apropiadas para su recuperación física y psicosocial ${ }^{112}$.

-Proporcionar a las víctimas menores y a los hijos de las víctimas acceso a la educación ${ }^{113}$.

-Designar a un tutor o representante legal del menor cuando un conflicto de intereses con el menor impidiera a los titulares de la responsabilidad parental defender el interés superior de éste o representarlo ${ }^{114}$.

-Prestar asistencia y apoyo, en la medida de lo posible, a la familia del menor cuando aquélla se encuentre en el territorio de un Estado miembro ${ }^{115}$.

La Directiva también entiende que la persona menor de edad víctima de trata debe ser tratada de una manera especial en el marco de las investigaciones y procedimiento para el esclarecimiento de estos delitos. En este sentido, el artículo 15 del texto legal establece:

-Que las autoridades competentes designen un representante del menor cuando el Derecho nacional retire la representación del menor a los titulares de la responsabilidad parental a causa de un conflicto de intereses entre éstos y el menor.

-Que el menor tenga acceso inmediato al asesoramiento jurídico gratuito y a la representación legal gratuita, incluso a efectos de reclamar una indemnización.

-Que los interrogatorios del menor víctima se celebren sin demoras injustificadas, en locales asignados o adaptados a tal efecto; que estén dirigidos por profesionales con formación adecuada, que se realicen siempre por las mismas personas, siempre que sea posible y conveniente, que el número de interrogatorios sea el menor posible y sólo cuando sea

\footnotetext{
${ }^{111}$ Artículo 13.2.

${ }^{112}$ Artículo 14.1.

${ }^{113}$ Artículo 14.1.

${ }^{114}$ Artículo 14.2.

${ }^{115}$ Artículo 14.3.
} 
estrictamente necesario para los fines de las investigaciones y procesos penales, que esté acompañado por su representante o un adulto elegido por él, salvo que por decisión motivada se haya excluido a esta persona.

-Que los interrogatorios de víctimas o testigos menores puedan ser grabados en video y que estas grabaciones puedan ser admitidas como pruebas en el proceso penal.

-Que la audiencia se celebre a puerta cerrada y que la víctima menor pueda ser oída sin estar presente en la sala, mediante el uso de las tecnologías de la comunicación adecuadas.

La Directiva también es consciente de la situación cada vez más generalizada de los menores migrantes no acompañados; niños, niñas y adolescentes que deciden emprender el viaje sin compañía de nadie bien porque no tienen familiares o tutores, bien porque éstos no pueden hacerse cargo de ellos y les animan a migrar, o bien porque inician el viaje simplemente sin el consentimiento de aquéllos. Esto les convierte indudablemente en un blanco fácil para los tratantes ${ }^{116}$. Para evitar estas situaciones, la Directiva obliga a los Estados miembros a adoptar medidas específicas que tengan en cuenta las circunstancias personales y particulares del menor no acompañado a la hora de prestarle asistencia y apoyo, exigiendo que se le nombre un tutor $^{117}$.

\section{Avances y retos pendientes}

Desde la adopción del primer instrumento legal supranacional contra la trata de personas, el Acuerdo internacional para la represión de la trata de blancas de 1904, hasta el último de ellos, la Directiva de la Unión Europea de 2011, han pasado algo más de cien años. En todo este tiempo, el concepto trata de personas, en general, y de menores, en particular, ha experimentado un notable cambio. Así, se ha superado la concepción más clásica que se centraba en la trata de mujeres con fines de explotación sexual únicamente $y$, hoy, ésta se concibe como una práctica multifacética que puede afectar a cualquier persona, mujer $u$ hombre, mayor o menor de edad, y que puede perseguir otras finalidades como la explotación laboral, la extracción de órganos, la utilización de la persona en actividades delictivas, los matrimonios forzados, las adopciones ilegales, la utilización de menores en conflictos armados, etc. Igualmente, se ha superado la creencia de que la trata debía tener un carácter transnacional, lo que había llevado durante mucho tiempo a confundir la trata con el tráfico ilícito de migrantes. Por último, en esta evolución del concepto de trata se ha superado la vinculación de la trata con el crimen organizado. Aunque esto

\footnotetext{
${ }^{116}$ Mier Hernández, A. y Rodríguez-Argüelles, S. (2011, p. 204).

${ }^{117}$ Artí́culo 16.
} 
sucede en numerosas ocasiones en la práctica, es importante subrayar que la trata no tiene que enmarcarse necesariamente en el contexto de la delincuencia organizada.

En relación con la noción específica de trata de menores, ésta también ha ido evolucionando a lo largo de este tiempo. En la actualidad, existe consenso internacional en torno a la idea de que, de los tres elementos clásicos de la definición de trata (acción, medios y finalidad), el relativo a los medios no es necesario en la trata de menores, ello debido principalmente a la especial vulnerabilidad de los mismos.

Durante este tiempo, y especialmente en la última década, el planteamiento sobre el que se basa la lucha contra la trata de seres humanos ha sufrido también una importante transformación. Tradicionalmente, se había promovido una repuesta penal, una respuesta centrada en el castigo, lo que había conducido al olvido de las necesidades de prevención y de protección de las víctimas y potenciales víctimas. Este enfoque empezó a vislumbrar un cambio importante durante los primeros años del nuevo milenio. Así, con la adopción del Convenio de Varsovia, se da un giro al abordaje de la trata, centrado ahora en la prevención y la protección, lo que se ha denominado enfoque victimocentrista, frente al enfoque punitivista previo ${ }^{118}$. El enfoque victimocentrista apuesta, además, por la inclusión de la perspectiva de género en el abordaje del fenómeno, habida cuenta de que las finalidades de explotación pueden diferir en función del sexo de la víctima ${ }^{119}$. Como se ha puesto de manifiesto supra, el nuevo enfoque prima también en la Directiva de la Unión Europea contra la trata de 2011.

En principio, este cambio de paradigma debe ser elogiado pues sitúa a los derechos humanos en el centro del discurso contra la trata de personas. Ello no obstante, las cifras orientativas sobre la magnitud del fenómeno demuestran que las medidas adoptadas e implementadas hasta el momento no son suficientes y óptimas para erradicar este fenómeno ${ }^{120}$. Ciertamente, las cifras sobre la dimensión de este fenómeno son alarmantes y ponen de manifiesto el fracaso de las políticas y acciones para prevenirlo y combatirlo.

En lo que a la trata de menores se refiere, tanto el Convenio de Varsovia como la Directiva de la Unión Europea tienen en especial consideración a este fenómeno, aspecto que había sido prácticamente ignorado en los instrumentos legales anteriores. Sin ánimo de reproducir aquí lo señalado en páginas anteriores, sí es preciso destacar que las medidas específicas sobre la trata de menores se pueden

\footnotetext{
${ }^{118}$ VILLACAMPA ESTIARTE, C. (2011a, p. 176).

${ }^{119}$ Así, en la Unión Europea, si nos centramos en la explotación sexual, el 95\% de las víctimas son mujeres, mientras que si nos centramos en la explotación laboral, el 71\% son hombres. EUROTAT (2015, p. 11).

120 Al hilo de esta cuestión, LARA AGUADO señala que en estos instrumentos legales «no hay un convencimiento de que lo verdaderamente prioritario en la lucha contra la trata es la víctima, porque ninguna de estas normas refleja la protección óptima» [LARA AGUADO, A. (2012, p. 69)].
} 
dividir en tres grupos: persecución, prevención y protección (conocidas como "3 P", por sus iniciales en inglés: prosecution, prevention and protection).

En lo relativo a la persecución y castigo de la trata de menores, debe destacarse que los dos últimos instrumentos aludidos entienden que deberá recibir más pena quien involucre a un menor en las conductas típicas de trata.

En lo referente a la prevención, los dos instrumentos subrayan la necesidad de abordar las causas que promueven la trata de menores (la pobreza, los conflictos armados, los desastres naturales, los movimientos migratorios, la discriminación, etc.), para lo cual es imprescindible la cooperación internacional. Igualmente, requieren que se lancen campañas de concienciación y sensibilización sobre el alcance de la trata. Son diversos los organismos internacionales y nacionales que han iniciado este tipo de campañas, sin embargo, aún queda mucho por hacer. Es preciso, por tanto, realizar campañas de concienciación específicas destinadas a las potenciales víctimas, advirtiéndoles de los riesgos de convertirse en víctimas de trata. Asimismo, es importante promover ese tipo de campañas en los centros escolares, por ejemplo, insistiendo en la igualdad y no discriminación; en otros locales o lugares a los que suelen acudir adolescentes y que pueden convertirse en centros de reclutamiento (bares, discotecas); y, también, en Internet. Al hilo de esta última cuestión, se considera que las redes sociales deberían advertir de los riesgos de convertirse en víctima de trata si se hace un mal uso de las mismas. Las campañas también deberían dirigirse a profesionales con probabilidad de entrar en contacto con víctimas o potenciales víctimas (trabajadores sociales, médicos, profesores, abogados, fiscales, jueces, inspectores de trabajo, policías, etc.) para que puedan identificarlas con más facilidad, así como a los demandantes de los servicios ofrecidos por las personas tratadas, recordándoles que la trata vulnera los derechos más básicos de las personas que la sufren, en especial, si son menores de edad. En este sentido, por ejemplo, deberían incluirse advertencias en las secciones de contacto de los periódicos o en las páginas webs y redes sociales de búsqueda de contactos. La prevención no debería olvidar, en último término, que niños y niñas pueden ser reclutados de maneras diferentes y con finalidades diferentes, por lo que las medidas adoptadas a este respecto han de tener presente la perspectiva de género ${ }^{121}$.

Por lo que respecta a la protección de las víctimas de trata menores de edad, de acuerdo con lo indicado en los instrumentos internacionales, pueden diferenciarse medidas antes, durante y después del proceso judicial.

Entre las medidas previas, hay que destacar las relativas a la identificación de los menores, debiendo ser considerado tal la persona respecto de la cual haya dudas sobre su edad existiendo, no obstante, razones para creer que es menor. En estos momentos previos, es vital identificar a quien es víctima de trata, pese a que haya sido

\footnotetext{
${ }^{121}$ Sobre esta cuestión, vid. LARA AGUADO, A. (2017, p. 827).
} 
detenida por la comisión de algún ilícito penal o administrativo. No hay que olvidar que las víctimas de trata, y en especial, los menores, pueden ser conminados a la realización de actividades delictivas por sus tratantes, conocedores éstos de la ausencia de responsabilidad o de una responsabilidad disminuida de los menores. Es esencial, por consiguiente, que se mejoren los mecanismos de identificación y que éstos no atenten contra la dignidad de las persona. Durante esos momentos iniciales, es crucial también, y así lo exigen los documentos internacionales referidos, otorgar a las víctimas la protección necesaria, ofreciéndoles alojamiento, manutención, cuidados médicos, escolarización, etc.; medidas que también deberían ser ofrecidas a la familia, cuando fuera posible. Estas medidas han de incluir permiso de residencia y período de reflexión y recuperación para los casos que involucren a víctimas de otros Estados. Más aún, la concesión de estas medidas no debe nunca hacerse depender de la colaboración de la víctima con las autoridades. Si el menor no estuviera acompañado, debe designársele un representante y proceder a la búsqueda de su familia.

Además, durante el proceso judicial, es indispensable evitar la victimización secundaria del menor, como la de cualquier víctima, evitando la repetición de entrevistas o interrogatorios y no exigiendo su presencia en la sala donde pueden estar sus victimarios.

En momentos posteriores al proceso judicial es, muy probablemente, donde más olvidadas quedan todas las víctimas. En consecuencia, los instrumentos internacionales y las legislaciones internas deberían hacer más hincapié en este punto, proporcionando el apoyo y la asistencia necesarias al menor y a su familia, facilitándoles la inserción en la sociedad o, si fuera su deseo, facilitándoles la repatriación a su lugar de origen, donde habrá que evitar que sean re-victimizadas, para lo cual es de suma importancia la cooperación entre Estados ${ }^{122}$.

Por terminar, conviene insistir en la necesidad de revisar el Protocolo de Palermo, dadas las carencias del mismo, ya comentadas en este trabajo. Si bien es cierto que dichas limitaciones han sido superadas en gran medida por el Convenio de Varsovia y por la Directiva de la Unión Europea, no debe olvidarse que el ámbito geográfico de aplicación de estos instrumentos es más reducido, encontrándonos en el momento actual con Estados de origen, tránsito o destino de menores víctimas de trata que sólo se encuentran obligados por el Protocolo de Palermo, el cual no exige apenas medidas de prevención y de protección de las víctimas y posibles víctimas. Igualmente, resulta necesario reconsiderar el alcance de determinadas disposiciones del Convenio de Varsovia y de la Directiva de la Unión Europea en aras de reforzar su efectividad.

\footnotetext{
${ }^{122}$ A este respecto, resulta de interés BRENNAN, D. y PLAMBECH, S. (2018, pp. 5-7).
} 


\section{Conclusiones}

A partir del estudio realizado, a continuación se exponen las principales conclusiones del mismo, dejándose las puertas a futuros trabajos de investigación.

Primera. La trata de menores, a pesar de ser un fenómeno antiguo, constituye en la actualidad un problema universal de alarmantes dimensiones que está presente en todas las regiones del mundo y que requiere respuestas urgentes y eficaces en aras de avanzar hacia su erradicación.

Segunda. El concepto de la trata de menores ha evolucionado considerablemente en las últimas décadas, de una noción estricta que solamente tenía en consideración la trata con fines de explotación sexual hacia una concepción más amplia en la que la trata se concibe como un fenómeno multifactorial cuya finalidad no se limita a la explotación sexual. Asimismo, se ha superado la convicción de que la trata debe implicar un cruce de fronteras internacionales y debe estar vinculada necesariamente con el crimen organizado.

Tercera. El Protocolo de Palermo (2000), el Convenio de Varsovia (2005) y la Directiva de la Unión Europea (2011) conforman, en la actualidad, el principal marco jurídico internacional para luchar contra la trata de personas, en general, y contra la trata de menores de edad, en particular.

Cuarta. La aprobación del Protocolo de Palermo constituye un hito en la lucha internacional contra la trata. Sin embargo, es un texto enmarcado en la lucha contra el crimen organizado que tiene un enfoque eminentemente punitivista y que olvida por completo a las víctimas, motivo por el cual debería ser revisado.

Quinta. El Convenio de Varsovia y la Directiva de la Unión Europea han suplido algunos de los vacíos jurídicos del Protocolo de Palermo y han adoptado un enfoque basado en los derechos humanos de las víctimas. A partir de la adopción de estos dos instrumentos, se consolida la visión de la trata como una grave violación de derechos humanos y comienza a ponerse atención en la prevención del fenómeno y en la protección de las víctimas.

Sexta. Sin perjuicio de los importantes avances alcanzados hasta el momento, la realidad evidencia que quedan muchos desafíos pendientes para lograr una efectiva prevención del fenómeno, para ofrecer una protección integral a las víctimas y para perseguir a los responsables. En especial, en relación con la prevención, resulta indispensable adoptar medidas que eviten la captación de menores que sean específicas dependiendo de las finalidades de la trata, pues éstas pueden ser diferentes en niños y en niñas $y$, por lo tanto, pueden requerirse especificidades. $Y$ en relación con la protección de las víctimas, se debe otorgar protección con independencia de su colaboración o no con las autoridades policiales y judiciales. 


\section{Referencias bibliográficas}

Aronowitz, A. (2009): Human Trafficking, Human Misery. The Global Trade in Human Beings (Connecticut, Global Crime and Justice).

Arrieta Idiakez, F.J., ManRiQue López, F. y MANRIQUe Rojo, F. (2011): «Combating trafficking in human beings for labour exploitation in Spain». En RIJKEN, C. (Ed.). Combating Trafficking in Human Beings for Labour Exploitation (Nijmegen. Wolf Legal Publishers).

BADIA MARTÍ, A.M. (2010): «La trata de niños en el ámbito jurídico internacional». En Aldecoa luzÁrRaga, F. y Forner Delaygua, J.J. (Dirs.). La protección de los niños en el Derecho Internacional y en las Relaciones Internacionales. Jornadas en conmemoración del 50 aniversario de la Declaración Universal de los Derechos del Niño y del 20 aniversario del Convenio de Nueva York sobre los Derechos del Niño (Madrid, Marcial Pons).

Boldova Pasamar, M.A., Urruela Mora, A., Libano Beristain, A., Bolaños Vásouez, H.J. y FARJAS BALLESTER, J.M. (2010): "Trata de seres humanos, en especial menores». En Revista de Derecho Migratorio y Extranjería, núm. 23, pp. 51-112.

BRENNAN, D. y PLAMBECH, S. (2018): «Moving forward -life after trafficking». En Anti Trafficking Review, núm. 10, pp. 1-12.

Daunis Rodríguez, A. (2013): El delito de Trata de Seres Humanos (Valencia, Tirant lo Blanch).

De LA CUeSTA ARZAMENDI, J.L. (2013): «Tráfico y trata de seres humanos: regulación internacional y europea». En RICHARD GONZÁLES, M., RIAÑO BRUN, I. y POELEMANS, M. (Coords.). Estudios sobre la Lucha contra la Trata de Seres Humanos (Cizur Menor, Aranzadi).

EUROSTAT (2015): Statistical Working Papers. Trafficking in human beings (Luxemburgo: Publication Office of the European Union).

Gallagher, A. (2001): «Human Rights and the New UN Protocols on Trafficking and Migrant Smuggling: A Preliminary Analysis». En Human Rights Quarterly, núm. 4 (vol. 23), pp. 975-1004.

-(2006): «Recent Legal Developments in the Field of Human Trafficking: A Critical Review of the 2005 European Convention and Related Instruments». En European Journal of Migration and Law, núm. 8, pp. 162-189.

-(2010): The International Law of Human Trafficking (Nueva York, Cambridge University Press).

GARCÍA CUESTA, S. (2012): «La trata en España: una interpretación de los derechos humanos en perspectiva de género». En Dilemata, núm. 10, pp. 45-64.

Gómez FernÁndeZ, I. y Pérez GONZÁlez, C. (2015): «La protección de los menores de edad víctimas de trata de seres humanos: Derecho internacional, Europeo y Español». En AlCÁCer Guirao, R., Martín Lorenzo, M. y Valle MarisCal de GANTE, M. (Coords.): La trata de seres humanos: persecución penal y protección de las víctimas (Madrid, Edisofer). 
GÓMEZ ISA, F. (2000): La participación de los niños en los conflictos armados. El Protocolo Facultativo a la Convención sobre los Derechos del Niño (Bilbao, Universidad de Deusto).

Jokinen, A., Viuhko, M., Nikkilä, M., Joutsen, M., CAmpana, P. y Benito, D. (2014): "Trafficking of human beings: report on enforcement statistics, with accessible factsheets». En MAfFel, S. y MARKOPOULOU, L. (eds.). FP7 Research Project for New European Crimes and Trust-based Policy (Atenas, EPLO).

LARA AGUADO, A. (2012): "La trata como grave violación de derechos humanos: incoherencias entre la concepción de la trata como atentado a los derechos humanos y su regulación a nivel interno e internacional». En LARA AGUADO, A. (Dir.) y Lara Aguado, A., Rueda ValdiviA, R. y Ruiz Sutil, C. (Coords.): Nuevos Retos en la Lucha contra la Trata de Personas con Fines de Explotación Sexual. Un enfoque interdisciplinar (Cizur Menor, Aranzadi).

-(2017): «El avance irresistible de la concepción de la trata como violación de derechos humanos: luces y sombras de las políticas protectoras de las víctimas en la normativa internacional e interna». En PÉREZ Alonso, E. (Dir.). El Derecho ante las formas contemporáneas de esclavitud (Valencia, Tirant lo Blanch).

LÓPEZ RODRÍGUEZ, J. (2016): Conceptualización jurídica de la trata de seres humanos con fines de explotación laboral (Cizur Menor, Aranzadi-Thomson Reuters).

Mier Hernández, A. y Rodríguez-Argüelles, S. (2011): "La trata de niños y niñas: estado de la situación actual». En Nova et Vetera 20(64), pp. 195-201.

Oficina de LAS NaCiOnes Unidas CONTRA LA DROGA y EL Delito (2016): Global Report on Trafficking in Persons 2016 (Nueva York, Naciones Unidas).

ORBEGOZO ORONOZ, I. (2013): «La trata de mujeres con fines de explotación sexual: una perspectiva victimológica y de género». En RICHARD GONZÁLES, M., RIAÑO BRUN, I. y Poelemans, M. (Coords.). Estudios sobre la Lucha contra la Trata de Seres Humanos (Cizur Menor, Aranzadi).

Organización Internacional del Trabajo (2002): Every Child Counts. New Global Estimates on Child Labour (Ginebra, Oficina Internacional del Trabajo).

-(2009): Training manual to fight Trafficking in children for labour, sexual and other forms of exploitation. Undertsanding child trafficking (Ginebra, Oficina Internacional del Trabajo).

ORgANIZACIÓN INTERNACIONAL PARA LAS MIGRACIONES (2012). Counter trafficking and assistance to vulnerable victims. Annual Report of Activities 2011 (Ginebra, Organización Internacional para las migraciones).

Pérez CEPEDA, A.I. (2004): Globalización, tráfico internacional ilícito de personas y derecho penal (Granada, Comares).

Pérez Cepeda, A.I. y Benito SÁnchez, D. (2014): Trafficking in Human Beings. A Comparative Study of the International Legal Documents (Groningen/Amsterdam, Europa Law Publishing).

PÉREZ GonZÁlez, C. (2014): «La protección de los menores víctimas de la trata de seres humanos: Algunas precisiones en torno al principio de diligencia debida». En Revisa de Derecho Migratorio y Extranjería, núm. 35, pp. 67-80. 
RODRÍGUEZ-PIÑERO Y BRAVO-FERRER, M. (2011): "La libertad de trabajo y la interdicción del trabajo forzoso». En Relaciones Laborales, Revista crítica de Teoría y Práctica, núm. 1, pp. 3-16.

SAX, H. (2018). "Child trafficking -a call for rights-based integrated approaches». En PIOTROWICZ, R., RIJKEN, C. y HEIDE UHL, B. Routledge Handbook of Human Trafficking. (Londres, Routledge).

SCARPA, S. (2008): Trafficking in human beings: modern slavery (Nueva York, Oxford University Press).

SYKIOTOU, A.P. (2007): Trafficking in human beings: Internet recruitment. Misuse of the Internet forthe recruitment of victims of trafficking in human beings (Estrasburgo, Consejo de Europa).

VELASCO PORTERO, M.T. (2012): «Los derechos en materia de extranjería de las mujeres y menores víctimas de la trata para la explotación sexual». En Aequalitas: Revista jurídica de igualdad de oportunidades entre mujeres y hombres, 2012, 31, pp. 6-14.

VILLACAMPA ESTIARTE, C. (2011a): El delito de Trata de Seres Humanos. Una incriminación dictada desde el Derecho Internacional (Cizur Menor, Aranzadi).

-(2011b). «La nueva Directiva europea relativa a la prevención y la lucha contra la trata de seres humanos y a la protección de las víctimas. ¿Cambio de rumo de la política de la Unión en materia de trata de seres humanos?». En Revista electrónica de ciencia penal y criminología, 13-14, pp. 1-52.

WYLIE, G. y MCREDMOND, P. (2010): «Introduction: Human Trafficking and Europe», en WYLIE, G. y MCREDMOND, P. (ed.). Human Trafficking in Europe. Character, Causes and Consequences (Nueva York, Palgrave Macmillan).

\section{Cómo referenciar este artículo/How to reference this article:}

López Rodríguez, J. (2019). El fenómeno de la trata de menores de edad en los instrumentos jurídicos internacionales: avances y retos pendientes. iQUAL. Revista de Género e Igualdad, 2, 41-72, doi: 10.6018/iQual.345751

López Rodríguez, J. (2019). El fenómeno de la trata de menores de edad en los instrumentos jurídicos internacionales: avances y retos pendientes. [Trafficking in children in the international legal instruments: progresses and pending challenges]. iQUAL. Revista de Género e Igualdad, 2, 41-72, doi: 10.6018/iQual.345751 